\title{
Application of Remote Sensing Technology in the Spatial Distribution of Regional Cities
}

\author{
Zhaodong Zhong ${ }^{1, a}$, \\ ${ }^{1}$ Planning and Design College, Xinyang Agriculture and Forestry University, Xinyang City, Henan \\ Province, 454000, China
}

Keyword: Remote sensing technology; Urban planning; Spatial distribution

\begin{abstract}
Remote sensing technology is an integrated technology using various sensing instruments to collect and process the radiation and reflection electromagnetic waves from a distant target in order to detect and identify all kinds of scenery on the ground. With the continuous development and improvement of modern remote sensing technology, remote sensing has produced a rich and accurate information, making it an important potential data source in urban planning. This paper first summarized the necessity and significance of remote sensing in urban planning, and then introduced the characteristics of remote sensing and its application in the analysis of urban planning layout information.
\end{abstract}

\section{The Necessity and Significance of Remote Sensing in Urban Planning}

A city is a multi-dimensional dynamic spatial structure entity, facing the problem of population pressure, resources, environment and development, therefore, the sustainable development of cities is the foundation of the sustainable development of the country. The development of modern city is based on information technology, intelligent technology, automation technology and so on. Informatization is the inevitable development of urban planning and management. The information content of the remote sensing image is very rich, including the visible information which can be distinguished by the naked eye, and the hidden information which is difficult to be distinguished, and the information which can not be expressed or processed by line drawings. It not only has the same mathematical accuracy of the same line drawing, but also can be used for professional interpretation, image interpretation and resource investigation, etc. The integrated information is processed by 
computer image processing with professional means, which gets all kinds of thematic maps, such as vegetation distribution map and land use map so that to provide the basis for city planning and design.

\section{Remote Sensing Applied to Urban Spatial Layout Information Analysis}

Analysis of urban built-up area and urban system. Because the urban built-up area reflects the macro characteristics of the city, the analysis does not require remote sensing image with a high spatial resolution; on the contrary, the spatial resolution is too high, so it will need more comprehensive mapping in the contour line extraction. In general, TM or SPOT images used to analyze the urban built-up area is more appropriate compared with other images; on the one hand, it can accurately reflect the scope of the built-up area; on the other hand, because of the synthesis of the image in the imaging process, it is easy to extract the contour line. If you want to analyze the relationship between a city and the surrounding city or town, Similarly, the choice of TM or SPOT image is more appropriate than other images. For example, in the TM image of the Shanghai area, the towns of all the townships (towns) where the government is located can clearly reflect their size and shape.

Analysis on the structure of urban land use. In satellite remote sensing images, the different types of urban land can be read out; first of all, it depends on whether it can be identified with the boundaries of the surrounding objects. If the size of the object is less than the spatial resolution of the image, it is very close to the background image, so the object will be mixed with the background, and it is impossible to interpret the object. In the case of the urban land, the boundary line can be reflected, and the type of urban land is further determined according to the image features (color, shape, size and texture) and correlation analysis. From three different spatial resolution satellite remote sensing images of TM, SPOT and IKONOS, TM image is more suitable for analysis of green land, water area, village and town construction land, newly built residential land and road square land, etc. However, it has poor accuracy of other land use. Compared with the TM image, the SPOT image has no essential difference in the content of the interpretation, but the accuracy and precision of the image are improved. Compared with the previous two kinds of images, the IKONOS image is essentially 
improved, and the characteristics of different urban land can be reflected on the image; as long as the interpreters are familiar with the area, the distribution of different types of urban land can be correctly detected.

From other satellite remote sensing data, CBERS data and TM data interpretation results are basically the same; the IRS - 1C panchromatic band data and TM multispectral data fusion image interpretation effect between SPOT and IKONOS data; the general road can be reflected in the image, and it can clearly identify the new residential land, a large plant industrial land and public facilities composed by high-rise buildings, etc.

Analysis of building density and floor area ratio. The preparation of urban building density map is usually based on block (block) drawing the outline of each building and calculating the area of the building; the size of the area and the area ratio of all the buildings in the block are the density of the building. To identify the boundary line of the building on the satellite remote sensing image is related to the distance between the buildings and the spatial resolution of the image. Generally speaking, the distance between buildings is greater than the image spatial resolution of 1.5 to 2 times, which can draw the line in the image contour line. For example, if the spatial resolution is $10 \mathrm{~m}$, the space between the buildings must be $15 \mathrm{~m}$ at least in order to delineate boundaries in the image. The building volume rate is the ratio of total land area and construction of buildings above the ground floor of all. There is a close relationship between the volume of construction and building height. In general, the altitude is higher, and the rate of volume is greater. The building height information obtained by satellite remote sensing technology began in early 1973. In general, there are two methods, including the drop shadow measurement and the stereo measurement. The principle of shadow measurement is a certain height of the object in the sunlight, which will produce the shadow on the ground; the length of the shadow is related to the height of the building and the scolar incident angle. When we know the solar incidence angle and the measure the length of the shadow so that you can calculate the height of the building. Star image can identify the minimum area of solid waste reaching 400 square meters, which can be used for the investigation of solid waste. 
Figure 1 is the application of Hyperspectral Remote Sensing Analysis of surface materials; according to the spectral characteristics of intuitive, it can distinguish different objects in city. This is a picture of the HyMap sensor recording the surface reflectivity of city; from the chart, the reflectivity of different materials in different bands are different. The blue one is a polyethylene roof, and the yellow one is tiled roof, while the following two are concrete and asphalt. We can see that in the 0.5 to 1.5 micron band, polyethylene roof has the highest reflectance, and the lowest reflectivity belongs to the asphalt.

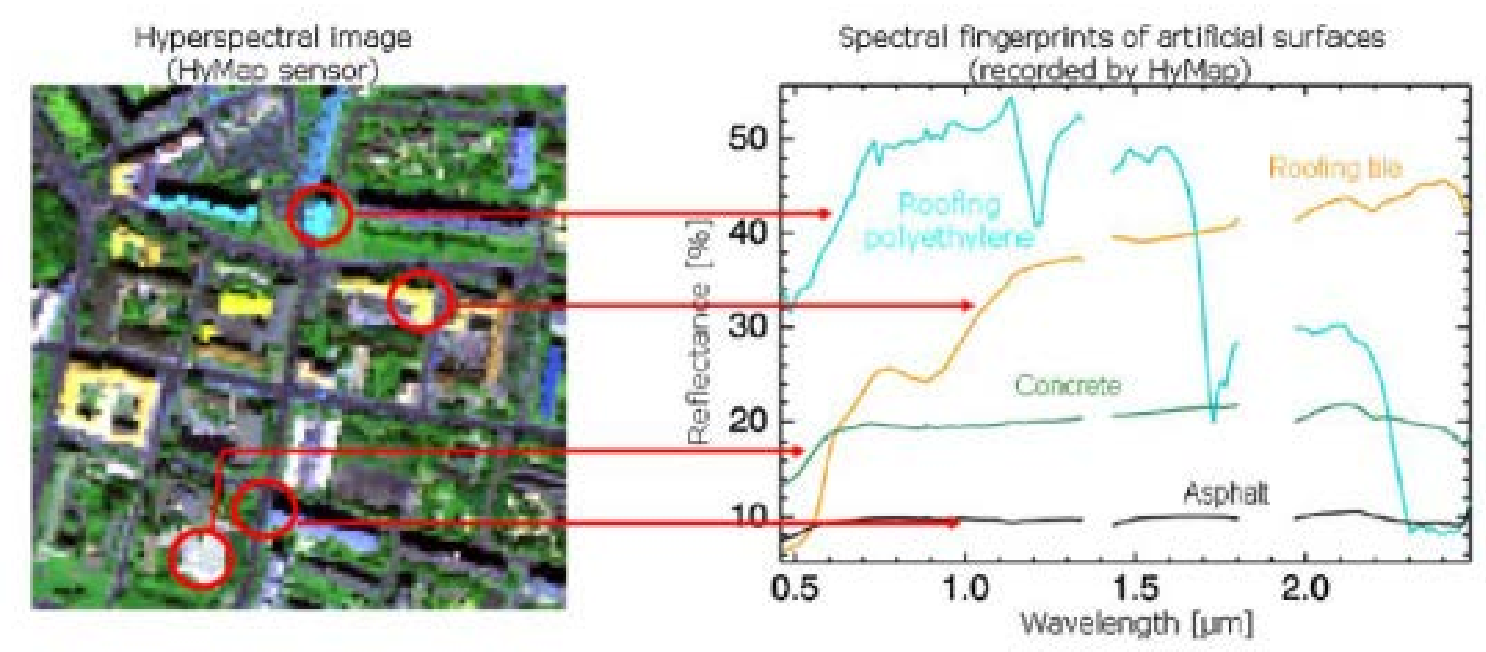

Fig.1: the application of Hyperspectral Remote Sensing analysis on surface materials

Figure 2 to 3 studys the application of remote sensing in the urbanization process of Hanoi, which is the capital of Vietnamese. From the beginning of 1990s, Hanoi industry began to develop rapidly, and the industry average annual GDP growth rate of 1991 to 1995 is $19.1 \%$, and $15.9 \%$ in 1996 to 2000, and 20.9\% in 2001 to 2003. In addition, there are 8 established industrial parks and 5 large industrial parks being under construction; it also has 16 small and medium-sized industrial groups. The non state-owned economy has a rapid expansion; according to the statistics in March 2007, the existing private business attaches to enterprises of 48000. Picture 2 is the image sensor MSS in 1975 with a resolution of 80 meters. Since 1975, the Vietnam War had just ended and most of the buildings were destroyed adding the low resolution of this map, so it is difficult to discern the road, the old city or large buildings. 


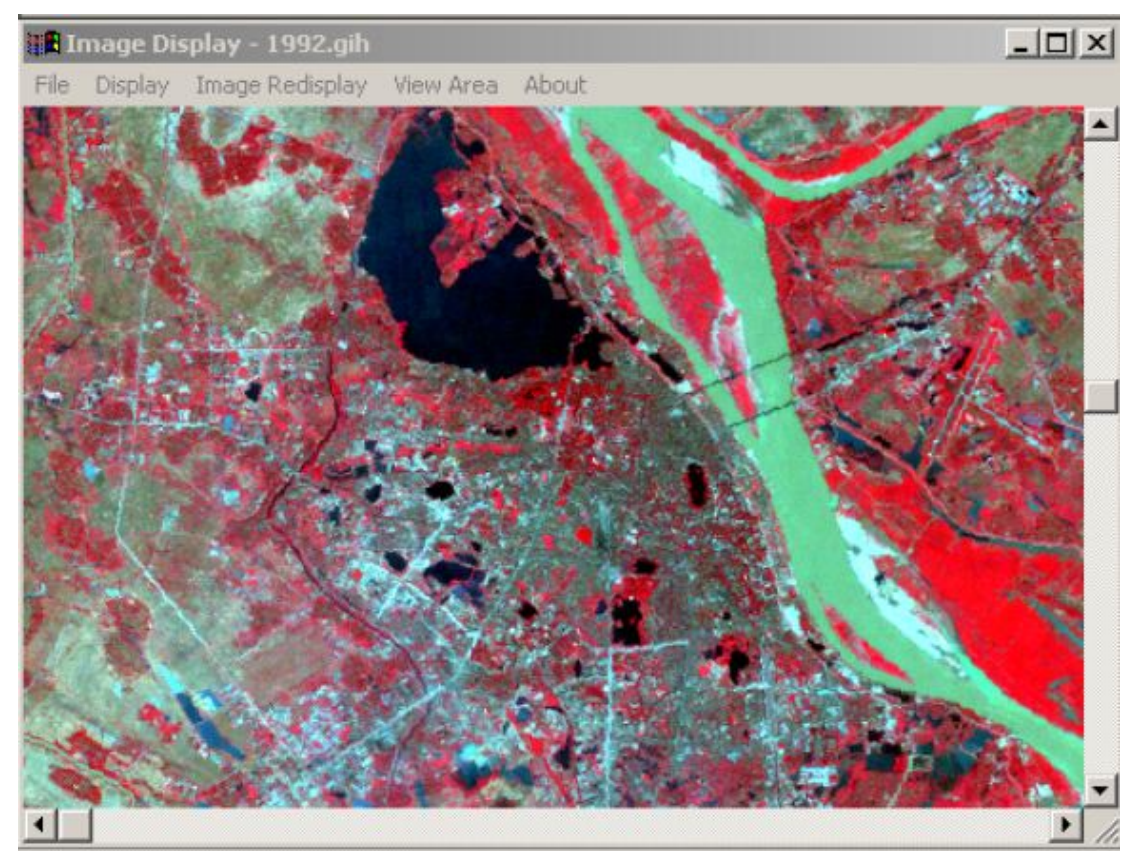

Fig.2: Hanoi’s MSS sensor image in 1975

But as time goes on, city has developmented; in 1992, we can clearly see the road in the city as shown in figure 3.

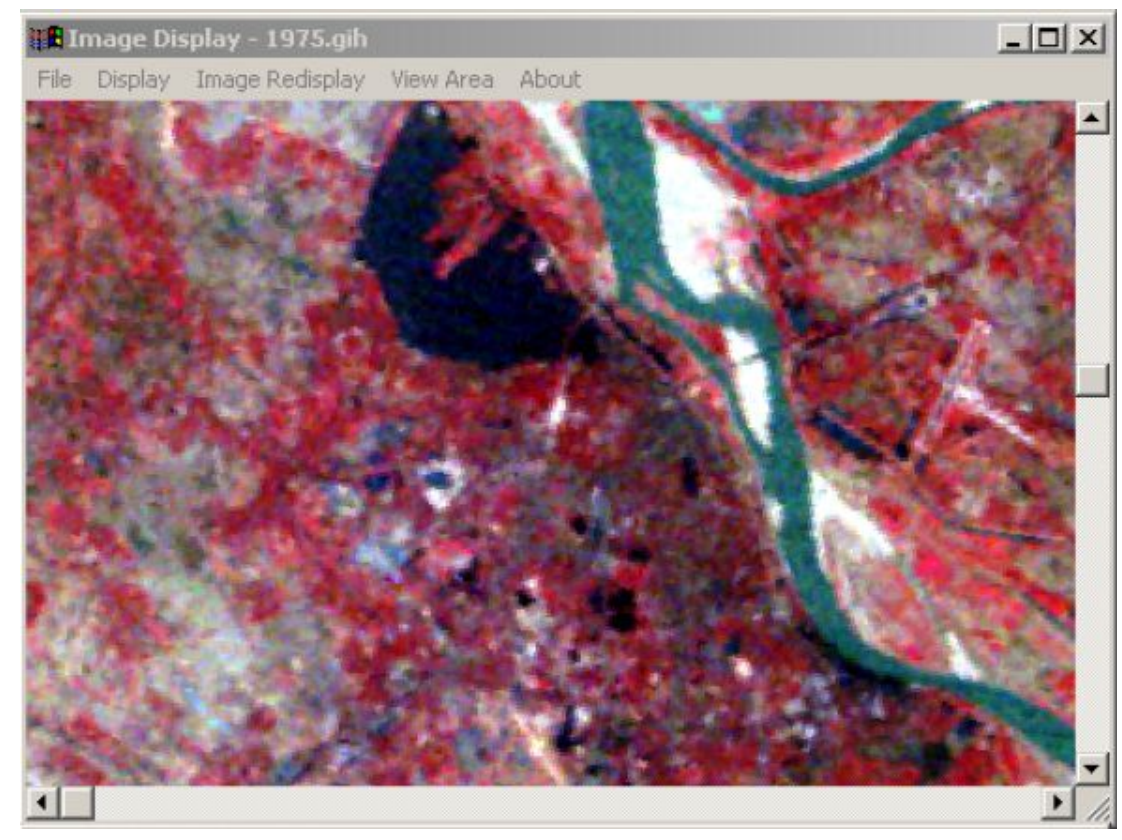

Fig.3: Hanoi’s MSS sensor image in 1992

By 2001, the economy developed rapidly; the obvious expansion appeared in just ten years in the city accompanied by angular building and road as shown in figure 4 . 


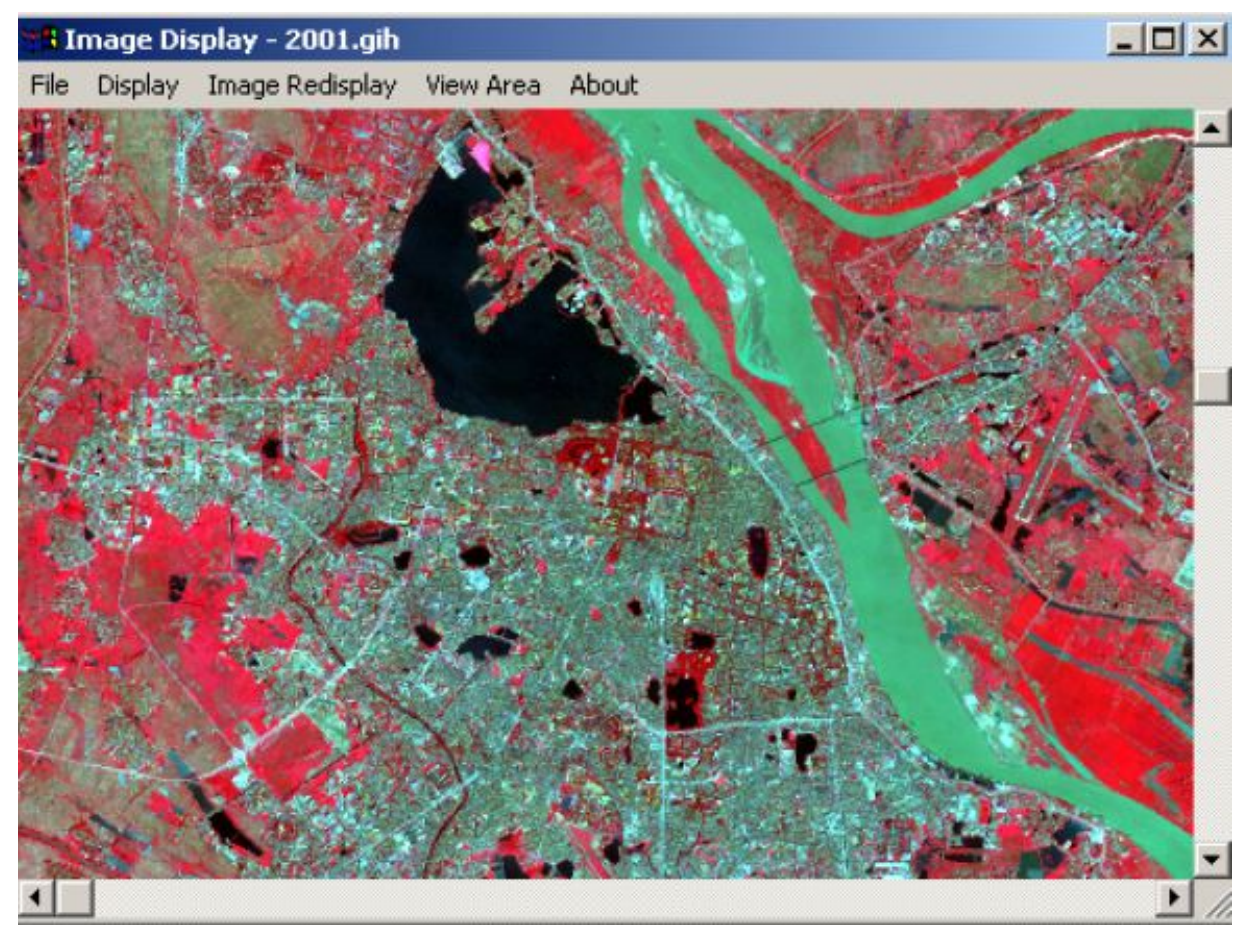

Fig.4: Hanoi’s MSS sensor image in 2001

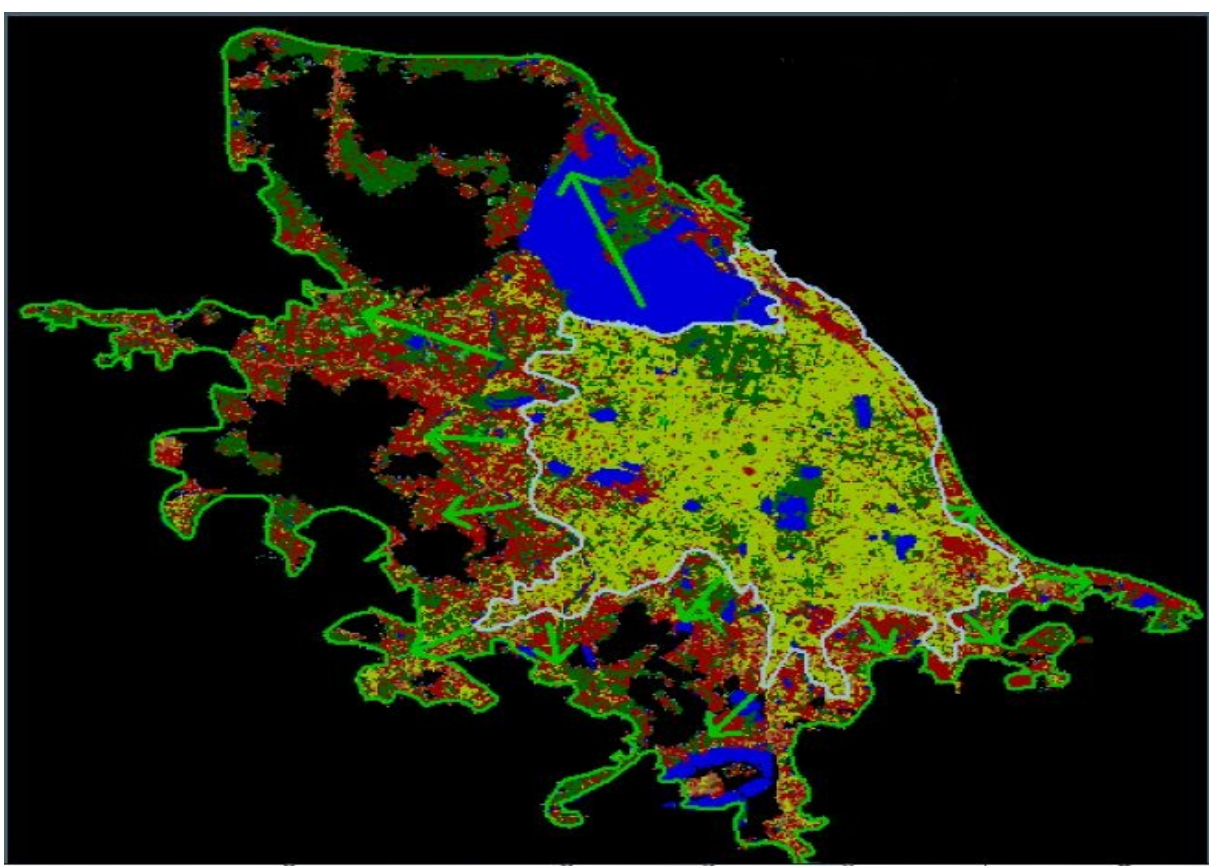

Fig.5: Hanoi city’s expansion (1992-2001)

Figure 5 is a reflection of the city expansion in Hanoi in 1992 and 2001, which is a capiyal city of Vietnamese. Inside, the white border belongs to 1992; outside, the green border belongs to 2001; the green arrow is the direction of expansion. Because the East River barrier, it cannot expand. According to statistical data, remote sensing data recorded by the proportion of change is also reflected in the GDP. With the expansion of the city, agricultural land reduced, and industrial GDP growth from 1996 
to 2000 was about $15 \%$ per year, while the agricultural GDP growth of 5.13\% in 1996 decreased to $3.8 \%$ in 2000 . We can see that in the past thirty years, Hanoi City area increased from 1000 hectares to 6000 hectares. It is the technology combined and processed by the remote sensing image in different period to acquire the dynamic changes of the earth and things. Detection methods can be divided into two categories: based on image classification, there are many methods, such as post classification comparison and multi-temporal image classification methods; based on single pixel spectral change, there are many methods, such as color synthesis method, image algebra method, multi-temporal data combination method, change vector method and two variation mask methods, etc. Land use information can be acquired through image processing technology, which extracts the rich and accurate information and draw the land use maps and various thematic maps. These maps are the important basises or basic maps for city planning and management of information.

\section{Conclusion}

Remote sensing technology is one of the most effective means to understand the basic information of the city. In recent years, people systematically build the auxiliary city planning analysis, special technology research and management platform by using remote sensing technology. In the using of new technology and research in the field of city planning, it has put forward the framework of the systematic and theoretical methods, and then been put into practice. Regularly carrying out city remote sensing integrated survey can provide important information for the city planning, management and construction. Similarly, for other aspects such as land, water conservancy, environment, landscape and tourism, it provides a comprehensive investigation as the basis for decision making. It is of great significance to maintain the sustainable development of the city. With the gradual expansion and deepening of the work, we believe that the remote sensing technology in the construction of each city in China will play a greater role.

\section{References}

[1]Guo Haichuan. Application of Remote Sensing Technology in the City Planning [J]. Technology 
and market,2016 (01): 83

[2]Wang Bihui. Remote Sensing in Thirty Years -- Remote Sensing Technology in the Practice of City Planning in Beijing[J]. Planning and Construction in Beijing, 2015, (02): 40-44.

[3] Kong Lengjin. High Resolution Remote Sensing Technology in the Application of the Digital City Planning[J].Global Positioning System, 2015, (01): 91-93.

[4] Zhang Ye. Discussion on City Land Planning Based on Remote Sensing Technology.[J]. private technology,2014, (12): 5

[5]Wang Xuhui . Remote Sensing Technology and Application in City Land Planning[J]. land resources in Shanghai, 2014, (01): 88-91.

[6] Wei Lai, Zhang Yongfa. Application of Satellite Remote Sensing Technology in the Management of City Planning[J].Intelligence, 2013 (34): 269-270. 